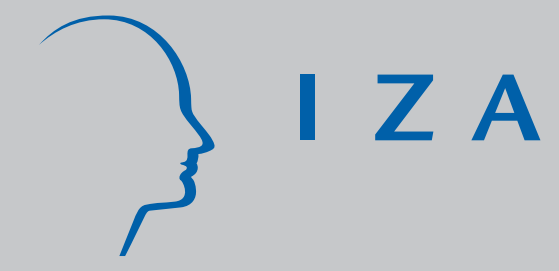

\begin{abstract}
IZA DP No. 157
Household Production, Full

Consumption and the Costs of Children
\end{abstract}

Patricia Apps

Ray Rees

May 2000 


\title{
Household Production, Full Consumption and the Costs of Children
}

\author{
Patricia Apps \\ Faculty of Law, University of Sydney, and \\ Economics, RSSS, Australian National University and IZA, Bonn \\ Ray Rees \\ Public Finance Institute, University of Munich
}

Discussion Paper No. 157

May 2000

\author{
IZA \\ P.O. Box 7240 \\ D-53072 Bonn \\ Germany \\ Tel.: +49-228-3894-0 \\ Fax: +49-228-3894-210 \\ Email: iza@iza.org
}

This Discussion Paper is issued within the framework of IZA's research area General Labor Economics. Any opinions expressed here are those of the author(s) and not those of the institute. Research disseminated by IZA may include views on policy, but the institute itself takes no institutional policy positions.

The Institute for the Study of Labor (IZA) in Bonn is a local and virtual international research center and a place of communication between science, politics and business. IZA is an independent, nonprofit limited liability company (Gesellschaft mit beschränkter Haftung) supported by the Deutsche Post AG. The center is associated with the University of Bonn and offers a stimulating research environment through its research networks, research support, and visitors and doctoral programs. IZA engages in (i) original and internationally competitive research in all fields of labor economics, (ii) development of policy concepts, and (iii) dissemination of research results and concepts to the interested public. The current research program deals with (1) mobility and flexibility of labor markets, (2) internationalization of labor markets and European integration, (3) the welfare state and labor markets, (4) labor markets in transition, (5) the future of work, (6) project evaluation and (7) general labor economics.

IZA Discussion Papers often represent preliminary work and are circulated to encourage discussion. Citation of such a paper should account for its provisional character. 
IZA Discussion Paper No. 157

May 2000

\section{ABSTRACT \\ Household Production, Full Consumption and the Costs of Children}

Recent work criticises both the logic and relevance of the theoretical basis of the approach to estimating the costs of raising children adopted in much of the economics literature. This tends to be restricted purely to models in which the household members consume market goods with given household income. The "costs of children" are perceived essentially as market consumption costs. This ignores the fact that an important, possibly preponderant element of child costs takes the form of parental time, which must be diverted from alternative uses such as market work, other house-hold production activities and leisure, to care for children. The studies also ignore the question of the distribution of income among adults and, in particular, the differential incidence of child costs on adult members of the household. In this paper we first of all argue that a satisfactory theoretical approach to modelling child costs must simultaneously incorporate an "individualistic" formulation of the household (as in Apps and Rees, 1988, 99) and a formal treatment of household production (as suggested by Becker 1965, and adapted in Apps and Rees, 1988, 99). We then provide such a model. Using data from a recent Time Use Survey, we estimate specialized versions of the model for families with two children and use the results to derive the intra-family distribution of resources and implied child-rearing costs.

JEL Classification: J13, J22, D13

Keywords: Child costs, time allocation, household production

Patricia Apps

Faculty of Law

University of Sydney

173/175 Phillip Street

Sydney NSW 2000

Australia

Tel.: +61293510241

Fax: +61293510200

Email: pfapps@law.usyd.edu.au 


\section{Introduction}

The need for a measure of the costs children create for a household arises in a wide range of policy contexts. Horizontal equity in taxation would seem to require that the tax levied on a given income should take account of whether that income has to support one person or two or more, including children. The goal of providing income support for the poor requires that the transfer a household receives will depend on the number of individuals it contains.

The method of estimating child costs that finds least favour with economists is that of estimating the costs of a child's physiologically determined "basic needs", for food, clothing, heat, shelter and so on. Indeed as both Browning (1992) and Nelson (1993) show this is the most common approach to equivalence scale calculation in the US and many other countries. Methodologically, economists dislike this approach because of its prescriptive, non choice-based nature and its implicit identification of "welfare" with a narrow set of measures of physical well-being. More substantively, it finds disfavour with those who stress that poverty and deprivation are relative concepts. To tie income support to the cost of achieving some minimum subsistence level is to define poverty in absolute physiological terms. On the other hand, a definition of poverty in relative terms requires estimation of the amounts households actually spend on their children. The cost of a child is an outcome of the choice of an intra-family distribution of consumption, that is, of how much consumption of all goods, including child care and other domestic outputs, a household chooses to allocate to its children at an equilibrium. This is the approach adopted in this paper.

The modelling approach to this estimation problem so far adopted in the literature is so narrow and in its empirical applications itself so ad hoc that it is not at all clear that any improvement over the physiologically-based approach has been made. The approach is to postulate a utility function or alternatively, an indirect utility function or expenditure function, in which children appear as parameters, and to define child costs as the amount of money which would have to be paid to hold utility constant as the "child parameters" vary. That is, we have a compensating variation measure of child costs, which can be put in terms of an equivalence scale by dividing it by the income the childless household or individual would require to achieve the same utility level. As Nelson (1993) makes clear this formulation implies a basic redefinition of the question that child cost measurement is designed to answer, and one which puts in question the policy relevance of the results. The policy concern is with the material welfare 
of each household member including, or especially, that of the children, and not simply the utility level of the adults. The main aim of policy is not simply to compensate adults for the amount of their consumption they choose to divert to their children. A further important policy issue is that of ensuring that transfers aimed at benefiting children actually reach them and do not just result in increased adult consumption. ${ }^{1}$ Under the "adult utility function" approach this is not even an issue, and the approach certainly does not provide an analytical framework within which it can be discussed. ${ }^{2}$

At the conceptual level, as against the level of policy relevance, at least as damning is the Pollak and Wales (1979) critique. This establishes first that the required compensating variations or equivalence scale index numbers cannot be estimated from the kinds of expenditure survey data usually used for the purpose; and secondly that if the true compensating variations are indeed estimated, the resulting "child costs" would in fact be negative and so would again be valueless for the kinds of purposes to which public policy wants to put them. If adults have children it must be because their utilities are higher with than without them, which implies a negative compensating variation. Despite this critique, a number of models have been applied to obtain estimates of equivalence scales. ${ }^{3}$ Results vary widely, with estimates of the "cost of a child" ranging from $12 \%$ to $100 \%$ of an adult's consumption. ${ }^{4}$

In this paper we try to broaden and re-direct the theoretical and empirical approach to the question of child costs. We reject the approach of defining child

\footnotetext{
${ }^{1}$ For example in the UK the system of tax allowances for dependent children was replaced by a system of direct cash payments on the grounds that the resulting transfer was more likely to be received by mothers and therefore more likely to result in increased consumption by children. The issue of transfers in cash or in kind can also be considered in these terms. In a model of the household as an individual, it is hard to refute the proposition that the recipient's welfare is always higher if transfers are in cash rather than in-kind. Once the household is viewed as a family, it is easy to see that transfers in cash and in-kind can have different effects on the intra-family consumption distribution, and those resulting from in-kind transfers may be judged better from the viewpoint of social policy.

${ }^{2}$ In other words there may well be a dissonance between the welfare weights individuals, here children, receive in a "household welfare function" and those they receive in a "social welfare function". For further discussion of this see Apps and Rees (1988).

${ }^{3}$ Excellent surveys of the main approaches - originating respectively with Engels, Rothbarth, Prais and Houthakker, Barten, and Gorman - are given in Browning (1992), Nelson (1993), and Pollak and Wales (1992). These also make clear the implausibility of the assumptions underlying each of the approaches.

${ }^{4}$ See table 2 in Browning (1992).
} 
costs as the amount required to hold parental utility constant. At the same time we take into account the fact that a major part of the costs of a child is the parental time that has to be diverted to it from other uses. Although this has long been recognised in the theoretical literature, it has been left out of empirical work on child costs. This work is based exclusively on consumption expenditure data, even though there is every reason to expect the expenditure of parental time to be even more important quantitatively than that on the child's consumption of market goods. Here we define the cost of a child in terms of its full consumption, ${ }^{5}$ that is, the sum of consumption of market goods, domestically produced goods, and parental time in the form of child care.

We present a model in which all household members, including children, are treated as individuals with their own utility functions. The approach is an extension of the individualistic formulation of the household's decision process in Apps and Rees $(1988,97,99)$. Adults choose allocations of their time over market labour supply, domestic production, child care and pure leisure. They also choose an allocation of market income over consumption goods and bought in inputs (including possibly child care) into the household production process. The central property of the time and consumption allocation is that it is Pareto efficient. Within the set of Pareto efficient allocations, market consumption goods and domestically produced consumption goods are allocated over the individuals in the household in a way which can be thought of as reflecting motivations such as love and caring for one another. ${ }^{6}$

The model addresses a further limitation of the existing literature. The standard approach to modelling family decisions does not take account of the basic diversity of household types, in respect of the market labour supply of the secondary earner, and the way this relates to the allocation of consumption to children. As we argue in Apps and Rees (1999), it is important to distinguish between what we

\footnotetext{
${ }^{5}$ This is by analogy with full income, the term used to denote the value of an individual's time endowment at her or his market wage.

${ }^{6}$ Within this approach it can be seen that the studies in the existing literature, which typically estimate models on total household consumption of market goods, in fact estimate the aggregrate demand for market goods by family members, including children. To observe how the aggregate demand varies with the number of children does not identify the consumption costs of children because the allocation of income to the adult members may change. The standard equivalence scale approach would, for example, understate child costs associated with market goods if the level of adult consumption fell as the number of children rose. The approach is also likely to give results indicating economies of scale when in fact none exist (see, for example, Kapteyn and Van Praag, 1976).
} 
call "traditional households', in which the secondary earner, usually female, works hardly at all outside the home, and "non-traditional households", in which the secondary earner's market labour supply is substantial, approaching that of the primary earner in the upper part of the distribution. ${ }^{7}$ We observe that in the former type of household, the consumption allocation of children consists of a much larger proportion of maternal child care and domestic production, and a much smaller proportion of market goods, than in the latter type of household. An approach which focuses on market consumption, as does the traditional equivalence scale literature, would therefore regard child costs as much lower in the traditional household, which clearly is absurd. This absurdity does not become obvious in the standard literature because it averages across household types, thus biassing estimates of true child costs downward. In this paper we maintain the distinction between the household types, not only because it gives a more accurate estimate of child costs, but also because it is interesting to observe the substitution between a child's consumption of domestic child care and household goods, on the one hand, and market goods, on the other, as we move between household types.

At a more basic level one must address the issue of why children cost their parents anything in the first place or, equivalently, why do parents need to transfer any income to their children? The standard analysis of intertemporal choice in a world of complete information and perfect markets is concerned with an individual's use of capital markets to determine an entire lifetime consumption stream given an endowed lifetime income stream. Why should that individual not be a child, or parent acting as the child's agent? This would imply that parents need not incur child costs. The problem is of course essentially one of contract incompleteness. There are considerable uncertainties surrounding the future income stream of a newly-born child, and it is prohibitively costly to write a contract, which would probably be non-enforceable, specifying an action for every possible contingency. There is also an agency problem - what would there be to stop a parent mortgaging the future income of the child to increase his or her own consumption? This is just one step away from selling the child into slavery. It is then this incompleteness in capital markets ${ }^{8}$ which creates the need for inter-generational transfers to cover child costs. But then the impossibility

\footnotetext{
${ }^{7}$ Here, as in Apps and Rees (1999), we explain the variation across households in market labour supply of the secondary earner in terms of her productivity in household production. This, in conjunction with her market wage, determines the implicit price of household production, and therefore the household's demand for domestic goods.

${ }^{8}$ This also seems to us to imply that models with child costs in which parents optimise over a lifetime facing perfectly competitive capital markets are internally inconsistent.
} 
of a contract by which a parent would be compensated for these costs from the future income of the child creates the possibility that the costs that would be incurred are not optimal from the child's point of view. This is not only to say that altruism may not be sufficient to achieve optimality for the child, but that the parent's own wealth constraint and preferences define the consumption and investment possibilities, especially in human capital formation, for the child. It is then possible to base the case for public intervention in support of child costs on the existence of these kinds of market incompleteness. ${ }^{9}$

The paper is organised as follows. In the next section we set out the theoretical formulation of a general model. In section 3 we present a simplified form of the model and an empirical specification. In section 4 we discuss data sources and further specialisations that are required to estimate a model on the available data, which include information on the time allocations of family members to domestic work, child care, and pure leisure from a time use survey. Section 5 presents the empirical results. In conclusion, in Section 6 we summarise the results and give an overview of the approach.

\section{The general model}

The model generalises Becker's (1965) model of household production by extending it to a multi-person household of adults and children. Moreover, we allow explicitly for variations in the time allocation of the secondary earner between household production and market work, reflecting variation in human capital and productivity in domestic work. The basic idea is that the household can be modelled as if it were a small economy, and the standard results of general equilibrium theory can be applied in a straightforward way.

The household buys a vector $x$ of market goods which it consumes directly, a vector $m$ of market goods which it uses as intermediate goods in domestic production, and it owns an initial endowment vector $\kappa$ of human capital inputs to domestic production. The household produces a vector $y$ of household private goods and a vector $g$ of household public goods. We identify domestic child care outputs explicitly as $d_{k}, k=1, \ldots, K$ where $K \geq 1$ is the number of children in the household. The household technology is assumed subject to non-increasing

\footnotetext{
${ }^{9}$ This implies that there is an efficiency argument, as well as a distributional argument, for transfers to families and children. Capital market failure of this kind, together with gender discrimination, can also have tax implications for the intra-family "terms of trade" between adults.
} 
returns and is given by the twice differentiable transformation function

$$
h\left(y, g, d_{1}, \ldots, d_{K}, m, t_{f}^{y}, t_{m}^{y}, t_{f}^{d}, t_{m}^{d} ; \kappa\right)=0
$$

where $t_{i}^{y}$ is the time $i$ spends on the production of household goods and $t_{i}^{d}$ is the time $i$ spends on child care, $i=f, m . f$ and $m$ are the two adults and only they supply time to household production. ${ }^{10}$

The utility functions of adults are defined on their consumptions of the vector of market goods, $x_{i}$, the vector of household private goods, $y_{i}$, pure leisure (a scalar), $z_{i}{ }^{11}$ and the vector of household public goods, $g$ :

$$
u_{i}=u^{i}\left(x_{i}, y_{i}, z_{i}, g\right) \quad i=f, m
$$

The utility functions of children are defined on market goods, $x_{k}$, household private goods, $y_{k}$, child care outputs, $d_{k}$, and household public goods, $g$ :

$$
u_{k}=u^{k}\left(x_{k}, y_{k}, d_{k}, g\right) \quad k=1, \ldots, K
$$

All utility functions are strictly quasi-concave and increasing, and at least twice continuously differentiable.

Each adult divides her or his time between general household production, child care, market labour supply $l_{i}$ and pure leisure. Thus we have the time constraints:

$$
t_{i}^{y}+t_{i}^{d}+l_{i}+z_{i}=T \quad t_{i}^{y}, t_{i}^{d}, l_{i}, z_{i} \geq 0 \quad i=f, m
$$

It is assumed that all of a child's time is pure leisure.

To complete the model we specify the household budget constraint. Corresponding to the vector $x$ is the given price vector $p$, and to the vector $m$ the given price vector $q$. Some market goods may of course be both final consumption and intermediate goods, in which case the corresponding elements of $p$ and $q$ will be identical. Given the market wage rates $w_{i}$ and non-wage incomes $\mu_{i}$, the budget constraint is

$$
p x+q m \leq^{\mathrm{X}}\left(w_{i} l_{i}+\mu_{i}\right)
$$

which can be equivalently written as the full income constraint

$$
p x+q m+{ }^{\mathrm{X}} w_{i}\left(t_{i}^{y}+t_{i}^{d}+z_{i}\right) \leq^{\mathrm{X}}\left(w_{i} T+\mu_{i}\right)
$$

\footnotetext{
${ }^{10}$ If domestic help is bought in then this is one of the market goods with the corresponding wage rate as its price. The essential assumption is that children do not contribute to domestic production.

${ }^{11}$ Alternatively, pure leisure could be treated as production for own-consumption, with an input of own time and domestic human capital.
} 
In principle we should impose reservation utility constraints on the problem. For the adults, these would have the interpretation that they represent minimum utilities that would have to be achieved in a household allocation to induce the individual to remain within the household. In general these will be functions of wage rates, individual non-wage incomes and other variables, not specified here, that determine the utility of "outside options" an individual may possess. For the children, they would correspond to minimum levels of consumption and child care which would be prescribed by law or social norms. ${ }^{12}$ In what follows we shall assume that at the household allocations we analyse these reservation constraints are satisfied as inequalities and so can be ignored. ${ }^{13}$

Note that the utility functions defined here are entirely "selfish": they include only own-consumption quantities. This is not to assume that parents do not care about each other or about their children, but simply that such caring does not affect their preference ordering over consumption quantities - there is a separability between these preferences and caring for other household members. Caring enters at the level of the determination of the household resource allocation, that is, it determines the given utility levels that are the constraints on the problem of finding a Pareto efficient allocation. Put another way, if we think of the household as maximising a "social welfare function" defined on individual utilities, the latter are "selfish" while the former incorporates all concerns household members may have for each other's welfare. It is then quite consistent with this approach to assume, as we do below, that individuals with children have the same ("selfish") preferences over consumption as individuals without children, even though their consumption patterns may differ substantially. ${ }^{14}$

The household acts as if it maximised the utility of one household member subject to given utility levels (by assumption strictly greater than the reservation levels just discussed) of all the others, and subject also to the constraints on the

\footnotetext{
${ }^{12}$ In fact we could think of the "physiological needs" studies as contributing to the definition of these constraints. We are assuming that in general children receive more than these minima at the household equilibrium allocation.

${ }^{13}$ We would expect that the economic analysis of issues involving poverty and divorce would require that these reservation constraints be carefully specified since they are likely to be binding or violated in such cases and so would play an important role in the analysis.

${ }^{14}$ An objection to this approach could be that we would expect my preferences over bundles containing beer and baby food to change when I acquire my first child. However, under the approach here, it is not my subjective preferences over own-consumption bundles that change. Rather, my child derives utility from baby food, and I place a weight on my child's utility as compared to my own, and it is this which determines my rate of substitution between beer and baby food and the corresponding allocation in the situation in which I have a child.
} 
domestic technology, time and expenditure given in (2.1), (2.4) and (2.5). Given our assumptions the first-order conditions for this problem are both necessary and sufficient for an optimum and can be straightforwardly described. Assuming all choice variables are strictly positive at the optimum we have:

- marginal rates of substitution between any pair of goods are equalised across household members;

- inputs are allocated so as to equalise their marginal value products in all uses;

- where both adults supply market labour, $i$ 's market wage ${ }^{15}$ measures the marginal value product of time $i$ spends in any household production activity and also the marginal (dollar) value of leisure;

- the Samuelson conditions characterise the production and consumption of household public goods, and in particular the optimal output of such a good equates its marginal cost to a weighted sum of its marginal utilities to the household members, where the weights (one of which is unity) are the Lagrange multipliers associated with the utility constraints in the problem ${ }^{16}$;

- the amount of care given to a child equates the marginal cost of this care to its weighted marginal utility, where the weight is again the appropriate Lagrange multiplier.

Applying the implicit function theorem to the first-order conditions for the problem we can solve for the vectors of demands, outputs and labour supplies as locally differentiable (in some cases vector) functions of prices, wage rates, non-wage incomes and capital stocks. All these functions are at least in principle observable. It is important to note that they are contingent on the particular distribution of the utilities of household members that underlies the formulation of the problem. This distribution reflects the outcome of the household decision process, and we expect that in general changes in prices, wages, and individual

\footnotetext{
${ }^{15}$ Where one adult supplies no market labour, the marginal value product of her/his time in household production is equal to the marginal value of leisure and is equal to or greater than the market wage.

${ }^{16}$ That is, an individual's weight in the household resource allocation, as measured by this multiplier, determines the extent to which her or his preferences for the household public good determine its total output.
} 
non-wage incomes (and not simply their sum) will cause changes in this outcome. Empirical observations on these demand and supply functions will therefore in general reflect changes in the weights given to the welfare of individual household members as well as the usual technology and taste parameters.

We can now define measures of the costs of children in the following way. By the Second Theorem of Welfare Economics (STWE), on the given assumptions there can be associated with the equilibrium allocation a set of implicit prices for the domestically produced private, public and child care goods, given by their marginal costs at the equilibrium. We can regard the household equilibrium quantities as being generated as if the household first distributed its full income amongst its members according to some distribution rule, giving income shares $s_{j}, j=f, m, k$ and $k=1, \ldots, K$. Then each member chooses consumption quantities by maximising her/his utility subject to a budget constraint defined by the explicit and implicit prices and these income shares. This determines a set of demand functions that are functions of these prices and income shares, and in the usual way an indirect utility function for each household member also defined on these prices and income shares. ${ }^{17}$

Let the vector of implicit prices of household private goods be denoted by $p$ and of household public goods by $\gamma$, and let $\tau_{k}$ denote the price of child care for the $k$ 'th child. Then the full consumption cost of child $k$ is given by

$$
C_{k}=p x_{k}+\pi y_{k}+\tau_{k} d_{k}+\gamma\left[g-g_{-k}\right]
$$

that is, by the cost of the bundle of market goods, domestic private and public goods and child care that the child consumes at the equilibrium household allocation. ${ }^{18}$

\section{Specification of an empirical model}

As a first step towards estimating a system within the framework set out above, we select a much simplified version of the model in which we have only four goods: a market good, a private domestic good, child care and pure leisure. We present

\footnotetext{
${ }^{17}$ For further discussion of this "decentralised" interpretation of the household equilibrium, which is a straightforward application of the STWE, see Apps and Rees (1988).

${ }^{18}$ Here $\gamma\left[g-g_{-\mathrm{k}}\right]$ is the cost associated with the increased demand for household public goods that an additional child imposes, with $g_{-\mathrm{k}}$ denoting the vector of household public goods that would be provided in the absence of child k. For example, housing space is a household public good, and its consumption is likely to increase with the number of children.
} 
the theoretical formulation of the simplified model and then provide an empirical specification.

\subsection{Theoretical formulation:}

The four goods, and their respective prices, are defined as: a market (composite) consumption good $x$ with a uniform price $p$ across households which is set to one; a private household good $y$ consumed by all family members with an implicit price of $\pi$ determined within the household; domestic child care $d$ with an implicit price of $\tau$; and pure leisure $z$, priced at the relevant market wage. The household comprises two adult members, $f$ and $m$, who allocate time to the production of the general household good, child care, market work and leisure, and a variable number of children. Children allocate their time to leisure only. The adult and child utility functions are now ${ }^{19}$

$$
\begin{gathered}
u_{i}=u^{i}\left(x_{i}, y_{i}, z_{i}\right) \quad i=f, m \\
u_{k}=u^{k}\left(x_{k}, y_{k}, d_{k}\right) \quad k=1, \ldots, K
\end{gathered}
$$

In addition to the constraints imposed by reservation utilities, the household's maximisation problem is subject to the domestic production, income and time constraints:

$$
\begin{gathered}
\mathrm{X} y_{j}=y \leq h^{y}\left(\kappa_{f}^{y} t_{f}^{y}, \kappa_{m}^{y} t_{m}^{y}\right) \quad j=f, m, k \quad k=1, \ldots, K \\
\mathrm{X} \quad d_{k}=d \leq h^{d}\left(\kappa_{f}^{d} t_{f}^{d}, \kappa_{m}^{d} t_{m}^{d}\right) \quad k=1, \ldots, K \\
\mathrm{X} \quad \mathrm{X} \quad\left(w_{i} l_{i}+\mu_{i}\right) \quad i=f, m \\
x_{i} \leq \quad t_{i}^{y}, t_{i}^{d}, l_{i}, z_{i} \geq 0 \quad i=f, m
\end{gathered}
$$

Here, $t_{i}^{y}$ and $t_{i}^{d}$ are $i$ 's time allocations to the production of the general domestic good $y$ and to child care $d$, respectively, and $\kappa_{i}^{y}$ and $\kappa_{i}^{d}$ are the domestic human capital inputs associated with these time allocations. We expect that the domestic human capital of each adult will vary across households. The income constraint in (3.5) can be written as the full income constraint

$$
\text { X }\left(x_{i}+w_{i}\left(t_{i}^{y}+t_{i}^{d}+z_{i}\right)\right)={ }^{\mathrm{X}} Y_{i}={ }^{\mathrm{X}} s_{j} \leq{ }^{\mathrm{X}}\left(w_{i} T+\mu_{i}\right)
$$

\footnotetext{
${ }^{19}$ Because of data limitations household public goods are excluded in the empirical analysis. This means that our results give a lower bound for child costs.
} 
where $Y_{i}$ is the full income of adult $i$ given by the data and $s_{j}$ is the implicit share in household full income of individual $j, j=f, m, k$ and $k=1, \ldots, K$, at the equilibrium allocation.

We assume that the household production functions (3.3) and (3.4) are linear homogeneous in the human capital and time inputs. This implies that the two domestic goods are produced according to the cost functions

$$
\begin{aligned}
& C^{y}\left(\omega_{f}^{y}, \omega_{m}^{y}, y\right)=c^{y}\left(\omega_{f}^{y}, \omega_{m}^{y}\right) y \\
& C^{d}\left(\omega_{f}^{d}, \omega_{m}^{d}, d\right)=c^{y}\left(\omega_{f}^{d}, \omega_{m}^{d}\right) d
\end{aligned}
$$

where $c^{y}(.,$.$) and c^{d}(.,$.$) are the unit cost functions and \omega_{i}^{y}=w_{i} / \kappa_{i}^{y}$ and $\omega_{i}^{d}=$ $w_{i} / \kappa_{i}^{d}, i=f, m$, are productivity adjusted wage rates. We then have implicit prices given by

$$
\begin{aligned}
& \pi=c^{y}\left(\omega_{f}^{y}, \omega_{m}^{y}\right) \\
& \tau=c^{d}\left(\omega_{f}^{d}, \omega_{m}^{d}\right)
\end{aligned}
$$

The human capital and time allocations to the two household production activities are given by

$$
\begin{array}{ll}
\left(\partial c^{y} / \partial \omega_{i}\right) y=\kappa_{i}^{y} t_{i}^{y} & i=f, m \\
\left(\partial c^{d} / \partial \omega_{i}\right) y=\kappa_{i}^{d} t_{i}^{d} & i=f, m
\end{array}
$$

\subsection{Empirical specification:}

To estimate the production side of the model we select the Translog as the functional form for the cost functions. We therefore have

$$
\begin{array}{rlrl}
\kappa_{i}^{y} t_{i}^{y} & =\left(c^{y} / \omega_{i}^{y}\right)\left(a_{i}^{y}(.)+{ }^{\mathrm{X}}\right. & \left.a_{i j}^{y} \ln \omega_{j}\right) y_{i} & i=f, m \\
\kappa_{i}^{d} t_{i}^{d}=\left(c^{d} / \omega_{i}^{d}\right)\left(a_{i}^{d}(.)+{ }^{\mathrm{X}}\right. & \left.a_{i j}^{d} \ln \omega_{j}\right) d_{i} & i=f, m
\end{array}
$$

for the domestic good and child care, respectively, where $a_{i}^{y}(),. a_{i j}^{y}, a_{i}^{d}($.$) and a_{i j}^{d}$ are parameters, $i, j=f, m$. We specify $a_{i}^{y}()=.\bar{a}_{i}^{y}(e)+\varepsilon_{i}^{y}$ and $a_{i}^{d}()=.\bar{a}_{i}^{d}(e)+\varepsilon_{i}^{d}$ where $e$ is a vector of control variables for the education attainment of each partner and $\varepsilon_{i}^{y}$ and $\varepsilon_{i}^{d}$ are normally distributed mean-zero error terms. The parameter pestrictions ${ }_{\mathrm{p}}$ are: $a_{i j}^{y}={ }_{\mathrm{P}} a_{j i}^{y}, a_{i j}^{d}=a_{j i}^{d}$ and, for linear homogeneity, $a_{i}^{y}()=$.1 , $a_{i j}^{y}=0, \quad a_{i}^{d}()=1,. \quad a_{i j}^{d}=0, i, j=f, m$. 
Given constant returns to scale, $\pi y={ }^{\mathrm{P}} w_{i} t_{i}^{y}$ and $\tau d={ }^{\mathrm{P}} w_{i} t_{i}^{d}$, and we have the share equations

$$
\begin{array}{lll}
w_{i} t_{i}^{y} l^{\mathrm{X}} w_{i} t_{i}^{y}=a_{i}^{y}(.)+{ }^{\mathrm{X}} a_{i j}^{y} \ln \omega_{j}^{y} & i=f, m \\
w_{i} t_{i}^{d} l^{\mathrm{X}} & w_{i} t_{i}^{d}=a_{i}^{d}(.)+{ }^{\mathrm{X}} a_{i j}^{d} \ln \omega_{j}^{d} & i=f, m
\end{array}
$$

The prices of the domestic goods are then computed as the exponent of their unit cost functions:

$$
\begin{aligned}
& \pi=c^{y}(.)=\exp \left(a_{0}^{y}(.)+{ }^{\mathrm{X}} \quad a_{i}^{y}(.) \ln \omega_{j}^{y}+0.5^{\mathrm{X}} \quad \mathrm{X} \quad a_{i j}^{y} \ln \omega_{i}^{y} \ln \omega_{j}^{y}\right) \\
& \tau=c^{d}(.)=\exp \left(a_{0}^{d}(.)+{ }^{\mathrm{X}} \quad a_{i}^{d}(.) \ln \omega_{j}^{d}+0.5^{\mathrm{X}} \quad \mathrm{X} \quad a_{i j}^{d} \ln \omega_{i}^{d} \ln \omega_{j}^{d}\right)
\end{aligned}
$$

where the intercept terms, $a_{0}^{y}($.$) and a_{0}^{d}($.$) , are functions of the respective female$ and male domestic human capital variables.

On the demand side we select the Almost Ideal (AI) demand system for estimation. The indirect utility functions for each adult $i$ and each child $k$ take the form:

$$
\begin{array}{r}
v^{i}\left(w_{i}, \pi, s_{i} ; \eta\right)=\ln \left(s_{i} / A_{i}\left(w_{i}, \pi ; v\right)\right) / B_{i}\left(w_{i}, \pi\right) \quad i=f, m \\
v^{k}\left(\pi, \tau, s_{k} ; \psi\right)=\ln \left(s_{k} / A_{k}(\pi, \tau ; \nu)\right) / B_{k}(\pi, \tau) \quad k=1, \ldots, K
\end{array}
$$

where the price indexes $A_{j}($.$) and B_{j}(),. j=f, m, k$, for $k=1, \ldots, K$, are given by $\ln A_{i}()=.a_{0}^{i}+a_{z}^{i}(.) \ln w_{i}+a_{y}^{i}(.) \ln \pi+0.5 \gamma_{z z}^{i} \ln ^{2} w_{i}+0.5 \gamma_{y y}^{i} \ln ^{2} \pi+\gamma_{z y}^{i} \ln w_{i} \ln \pi$

$$
\begin{gathered}
\ln A_{k}(.)=a_{0}^{k}+a_{y}^{k}(.) \ln \pi+a_{d}^{k}(.) \ln \tau+0.5 \gamma_{y y}^{k} \ln ^{2} \pi+0.5 \gamma_{d d}^{k} \ln ^{2} \tau+\gamma_{y d}^{i} \ln \pi \ln \tau \\
B_{i}(.)=w_{i}^{\beta_{z}^{i}} \pi^{\beta_{y}^{i}} \\
B_{k}(.)=\pi^{\beta_{y}^{k}} \tau_{d}^{\beta_{d}^{k}}
\end{gathered}
$$

and $\alpha_{0}^{i}, \alpha_{g}^{i}(),. \gamma_{g g}^{j}, \gamma_{g h}^{j}, \gamma_{h g}^{j}$ and $\beta_{g}^{j}$ are parameters, $g, h=z, y, x$ for adult $i$ and $g, h=y, d, x$ for child $k$. We specify

$$
\begin{array}{ll}
\alpha_{g}^{i}(.)=\bar{\alpha}_{g}^{i 0}+\alpha_{g}^{i 1} \ln \eta & i=f, m \\
\alpha_{g}^{k}(.)=\bar{\alpha}_{g}^{k 0}+\alpha_{g}^{k 1} \ln \psi & k=1,2
\end{array}
$$

where $\eta$ is the average age of adults and $\psi$ is the $\mathrm{p}_{\mathrm{p}}$ age of youngest child. The parameter restrictions required for adding up are $\alpha_{g}^{j}()=1,. \quad \beta_{g}^{j}=0$, and 
$\Sigma \gamma_{g h}^{j}=0$; for symmetry, $\gamma_{g h}^{j}=\gamma_{h g}^{j}$; and for homogeneity, ${ }^{\mathrm{P}} \gamma_{h g}^{j}=0, j=f, m, k$ and $k=1, \ldots, K$.

Individual demands in share form are given by

$$
\begin{array}{cc}
S_{z}^{i}=\alpha_{z}^{i}(.)+\gamma_{z z}^{i} \ln w_{i}+\gamma_{z y}^{i} \ln \pi+\beta_{z}^{i} \ln \left(s_{i} / A_{i}(.)\right) & i=f, m \\
S_{y}^{i}=\alpha_{y}^{i}(.)+\gamma_{y z}^{i} \ln w_{i}+\gamma_{y y}^{i} \ln \pi+\beta_{y}^{i} \ln \left(s_{i} / A_{i}(.)\right) & i=f, m \\
S_{y}^{k}=\alpha_{y}^{k}(.)+\gamma_{y y}^{k} \ln \pi+\gamma_{y d}^{k} \ln \tau+\beta_{y}^{k} \ln \left(s_{k} / A_{k}(.)\right) & k=1, \ldots, K \\
S_{d}^{k}=\alpha_{d}^{k}(.)+\gamma_{d y}^{k} \ln \pi+\gamma_{d d}^{k} \ln \tau+\beta_{d}^{k} \ln \left(s_{k} / A_{k}(.)\right) & k=1, \ldots, K \\
S_{x}^{i}=\alpha_{x}^{i}(.)+\gamma_{x z}^{i} \ln w_{i}+\gamma_{x y}^{i} \ln \pi+\beta_{x}^{i} \ln \left(s_{i} / A_{i}(.)\right) & i=f, m \\
S_{x}^{k}=\alpha_{x}^{k}(.)+\gamma_{x y}^{k} \ln \pi+\gamma_{x d}^{k} \ln \tau+\beta_{x}^{k} \ln \left(s_{k} / A_{k}(.)\right) & k=1, \ldots, K
\end{array}
$$

where $S_{z}^{i}=w_{i} z_{i} / s_{i}, S_{y}^{j}=\pi y_{j} / s_{j}, S_{d}^{k}=\pi y_{k} / s_{k}$ and $S_{x}^{j}=x_{j} / s_{j}, j=f, m, k$ and $k=1, \ldots, K$.

Given this specification the full consumption cost of child $k$ can be computed as

$$
C_{k}=p x_{k}+\pi y_{k}+\tau d_{k}
$$

and the full consumption cost of an adult as

$$
C_{i}=p x_{i}+\pi y_{i} \quad i=f, m
$$

A full consumption equivalence scale for child $k$ with respect to adult $i$ can be computed as

$$
E_{i k}=C_{k} / C_{i} \quad k=1, \ldots, K
$$

where, in general, we would expect this measure to vary with both $i$ and $k$. Note that such a "scale" is simply a measure of relative full consumption expenditures financed from income shares that a household chooses to give its members.

\section{Data}

Estimation of the empirical model specified in the preceding section requires data on the following sets of variables:

- time allocations to market work, domestic work and child care 
- individual consumptions of the market good, domestic good, child care and pure leisure

- wage rates, non-labour incomes and domestic human capital

There are no micro datasets which contain information on all these variables, or which allow them to be instrumented.

Labour supply and consumption demand systems, as well as equivalence scales, are typically estimated on datasets drawn from household expenditure or income survey files providing information on market hours of work, wage rates and nonlabour incomes. Importantly, data on hours of domestic work and pure leisure are missing, as are data on individual consumptions of market goods and domestic output, and on domestic human capital. To deal with missing information on hours of domestic work and pure leisure, the convention is to compute, either implicitly or explicitly, the time each adult allocates to non-market activity as the difference between total time available and market hours of work. Non-market hours computed in this way, although referred to as female and male "leisures", are the sum of time allocations to domestic work, child care and pure leisure. And because domestic work and child care benefit family members other than those who contribute their time to these activities, the datasets contain no information on individual consumptions of domestic outputs as well as pure leisure.

An important purpose of the empirical work in this paper is to show how data on domestic work, child care and pure leisure available from a time use survey can be used to improve the estimation of models of family labour supply and commodity demands, by providing information on intra-family consumptions of leisure and child care. Inevitably we are faced with missing information on individual consumptions of domestic outputs and the market good, and so it is necessary to specialise the model in a number of important respects. We want to make as clear as possible how and why this must be done, and to show that previous empirical work on family labour supply and demand behaviour must also be based on assumptions concerning these and other missing variables.

We estimate specialised versions of the model on a dataset containing daily time allocations of family members, wage rates and non-labour incomes. The information on time use is drawn from the Australian Bureau of Statistics (ABS) 1992 Time Use Survey (TUS). The survey collected diary data on the allocation of time to all activities during the day. However, labour income was not recorded separately from other sources of income, and so information on wage rates and exogenous income is missing. We therefore need to combine data on these variables 
with the time use information in the TUS. For this purpose we draw on the ABS 1990 Income Distribution Survey (IDS) containing hours of market work, wages and salaries and non-labour incomes. The two samples provide complimentary datasets for the same underlying population. Both include detailed information on the same set of demographic characteristics of family members, on their levels of education and on other characteristics.

The IDS provides a relatively large sample of approximately 19000 "income unit" records (referred to here as households) of which almost half represent records containing two adults ("non-dependent persons") with and without dependents. ${ }^{20}$ The TUS contains approximately 3000 household records. The survey collected detailed data on the allocation of time to activity episodes by diary, for two diary days. The activity episode classification distinguishes between market labour supply and nine major categories of non-market activities, and includes information for up to three simultaneous "primary", "secondary" and "tertiary" activities. $^{21}$

We select a sample of households comprising two children and two parents from the files for each of these surveys, on the following criteria: the "reference" person is male and employed full time, defined as 1700 hours per annum (pa); household income is primarily from earnings (households with income primarily from partnerships, own business or farms are excluded); both partners are aged from 20 to 49 years; and at least one child is under 14 years. The IDS sample contains 1053 records and the TUS, 353 records. We split both samples into "traditional" and "non-traditional" households. The former are defined as those in which the female partner works less than 500 hours pa in the market place and the latter as those in which she is employed for 500 hours or more pa. The number of records in the traditional and non-traditional subsamples is 572 and 481 in the IDS and 178 and 175 in the TUS, respectively.

Because information on individual consumptions, apart from pure leisure, is missing, individual preference parameters cannot be identified without additional assumptions (see Apps and Rees, 1997). To identify the preference parameters of family members, we first of all assume that adults have the same preference parameters for domestic and market goods and that children have the same preferences for all goods. With these restrictions we still cannot identify adult and

\footnotetext{
${ }^{20}$ The two non-dependent persons are referred to as the "reference person" and "spouse". Dependents are defined as unmarried persons living with their parent(s) and either under 15 years of age or full-time students aged 15 to 20 years.

${ }^{21}$ For details of the classification categores see ABS (1993).
} 
child preference parameters and, of course, we do not wish to assume that they are the same. To deal with this problem we adopt the approach of Gronau (1991). We obtain adult preference parameters by first estimating the model on data for a sample of two-adult households without children. The approach depends on the assumption that adults who do not yet have children have the same "selfish" preferences over own consumptions bundles as those who do. Given adult preference parameters, we can then estimate the child parameters on the dataset for the two-child households.

To implement the Gronau approach we require matching samples of households without children. We select these samples on the same criteria as specified for the two-child households, apart from age and the employment status of the female partner. In order to ensure as far as possible that the records represent couples who have not yet had children, we select the matching samples on the more restrictive criteria that the male partner is aged from 20 to 35 years and the female partner is employed for 500 hours p.a. or more. The sample drawn from the IDS contains 425 records and from the TUS, 153 records

Table 1 reports data means for the variables of main interest in these matching samples. The first two columns give means for two-child traditional and non-traditional households, and the third column reports means for households without children. Rows 1 to 6 give IDS data means for female and male hours of market work, gross wages and non-labour incomes, for the two household types. The measure of the gross wage for a participant working 500 hours or more is gross hourly earnings computed from the data on hours and wages and salaries. The gross wage for the female partner in the traditional household is predicted using the Heckman procedure. ${ }^{22}$ Rows 7 to 12 present TUS data means for female and male hours of domestic work, child care and pure leisure. Domestic work is computed as the sum of time allocations to the categories "domestic activities" and "purchasing goods and services". The category "child care/minding" is treated as time spent on domestic child care. Hours of pure leisure are computed as the sum of time allocations to remaining non-market activities, less 8 hours per day. ${ }^{23}$ To use the information on primary, secondary and tertiary activities we apply a

\footnotetext{
${ }^{22}$ In the estimation of the wage equation the Heckman procedure is applied to correct for sample selection bias, explaining whether a female partner works 500 hours or more in terms of specified market and reservation wage variables. The lower bound of 500 hours is chosen in order to reduce measurement error in gross hourly earnings arising from limitations of the data for those working fewer hours.

${ }^{23}$ The reason for subtracting 8 hours is that we set total time available, T, to 16 hours per day (5840 hours pa) in the estimation of the demand system.
} 
set of weights which sum to one for a given activity episode. ${ }^{24}$

Table 1 [here]

We use split-sample instrumental variables (SSIV) as a method for combining information from the complementary IDS and TUS datasets. Ideally, we would like to estimate the model on the TUS samples using instruments for missing wage and non-labour income variables estimated on the IDS samples. ${ }^{25}$ However, this approach encounters a number of difficulties. Very poor instruments for the missing wage and non-labour income variables are obtained from the IDS sample, a common result for cross section data. In addition, the TUS sample, while relatively large for a time use dataset, is much smaller than the IDS sample. The potential for serious small sample parameter bias arises from the combined effect of this and the fact that the diary data in the TUS are collected for two days which may be week or weekend days. Data on daily time use of this kind exhibits much greater variation than that collected on a weekly basis.

For these reasons we adopt a procedure which is consistent with the standard approach to the estimation of labour supply models on data sets with missing information on hours of non-market activity. We estimate the model on the much larger IDS samples instrumenting for the missing time use variables. For households without children, we instrument for pure leisure, using variables such as age and level of education, and compute domestic hours of work from the time constraint. A limitation of the approach is that errors in domestic hours will be negatively correlated with observation errors in hours of market work. The same problem arises in modelling family labour supply on data for market hours alone, computing non-market hours from market hours and a time constraint. ${ }^{26}$ The gain in the present context is that we use information from a time use survey to avoid, in effect, setting pure leisure hours to zero or an arbitrary constant. In the case of two-child households we instrument for pure leisure using education and the ages of the children as well as of the adults. We instrument for domestic work

\footnotetext{
${ }^{24}$ Where primary and secondary activities are reported, the weighting applied is 0.7:0.3, respectively, and where primary, secondary and tertiary activities are reported, the weighting used is $0.65: 0.25: 0.1$, respectively.

${ }^{25}$ This procedure is adopted in studies such as Angrist and Kruger (1992) and Arrellano and Meghir (1992).

${ }^{26}$ It is worth noting that the TUS file, unlike the datasets used for the estimation of family labour supply models, contains information on every activity during the day. Although the ABS made every effort to ensure that the time constraint was satisfied, it was not possible to do so in all cases. The TUS also contains hours of market work obtained by interview. The reported hours typically do not match perfectly the time recorded by diary.
} 
using the same variables and, in addition, controlling for household type. We then compute hours of child care from the time constraint. Table 2 reports the means for the variables of interest in the merged datasets, for non-traditional and traditional households with children and for households without children. Rows 1 to 3 give the means for female and male time allocations to domestic work, child care and pure leisure. Row 4 reports expenditures on pure leisure and row 5, the expenditure on child care for each child $k, k=1,2$, in the two types of households.

Table 2[here]

The means reported for time allocations are of particular interest, for two reasons. First, while the female partner in the traditional household allocates little or no time to market work, the means suggest that she allocates much more time to work and child care at home than the female partner in the nontraditional household. The result is that, although the labour supplies of the two household types are observed to vary widely, their overall work-leisure hours do not. From this we might infer that the two household types have similar work-leisure preferences, but make different market and domestic goods choices in response to price variation in the latter due to differences in domestic human capital.

Second, the mean leisure hours of both partners in households without children are almost equal. However, with the arrival of children, the means leisure hours of the female partner in both household types fall more than those of the male partner. These data means for pure leisure, together with the assumptions on adult preference parameters for the market and domestic goods detailed in the following section, tend to drive the results for the intra-family distribution of income and consumption of the market and domestic goods for which data are missing.

\section{Empirical model and Results}

With missing information on adult and child consumptions of the market and domestic goods we are limited to estimating a system which specifies aggregate household shares for these goods and an intra-family distribution rule. Data on domestic human capital is also missing and so domestic prices can be derived only on the basis of assumptions about the productivity of domestic time. This section first of all sets out the empirical specification of the production and demand sides of the model to deal with these problems and then presents results. 


\subsection{Production system}

Estimation of the parameters of the Translog production functions, (3.16) for the domestic good and (3.17) for child care, requires information on the productivity adjusted wage rates $\omega_{i}^{y}=w_{i} / \kappa_{i}^{y}$ and $\omega_{i}^{d}=w_{i} / \kappa_{i}^{d}, i=f, m$. Since we have no data on the $\kappa_{i}^{y}$ and $\kappa_{i}^{d}$ we are restricted to estimating the production shares as

$$
\begin{aligned}
& \left.w_{i} t_{i}^{y}\right|^{\mathrm{X}} w_{i} t_{i}^{y}=a_{i}^{y}(.)+{ }^{\mathrm{X}} a_{i j}^{y} \ln w_{j}+\xi_{i}^{y} \quad i=f, m \\
& w_{i} t_{i}^{d}{ }^{\mathrm{X}} w_{i} t_{i}^{d}=a_{i}^{d}(.)+{ }^{\mathrm{X}} \quad a_{i j}^{d} \ln w_{j}+\xi_{i}^{d} \quad i=f, m
\end{aligned}
$$

where

$$
\begin{array}{ll}
\xi_{i}^{y}=-{ }^{\mathrm{X}} & a_{i j}^{y} \ln \kappa_{j}^{y}+\varepsilon_{i}^{y} \\
\xi_{i}^{d}=-{ }^{\mathrm{X}} & a_{i j}^{d} \ln \kappa_{j}^{d}+\varepsilon_{i}^{d}
\end{array}
$$

Here we wish to allow varying degrees of specialisation in domestic production to reflect price variation due to differences in domestic human capital ratios within the household, $\kappa_{m}^{y} / \kappa_{f}^{y}$ and $\kappa_{m}^{d} / \kappa_{f}^{d}$, as well as differences in overall levels of domestic human capital across households. We therefore set $\varepsilon_{i}^{y}=0$ and $\varepsilon_{i}^{d}=0 .{ }^{27}$ This assumption implies that, ceteris paribus, a partner (typically the female) will tend to specialise in household production if she is relatively more productive in that activity. ${ }^{28}$ Overall differences in domestic productivities due to differences in $\kappa_{i}^{y}$ and $\kappa_{i}^{d}$ across households are captured in the intercept term of the unit cost functions. Prices which generate predicted demands consistent with the data are derived by solving iteratively for the intercept term, and then substituting the result for each record.

\subsection{Demand system}

The model estimated on the dataset for two-child households contains five expenditure equations in share form: male and female pure leisure expenditures, the aggregate consumption expenditures of adults and children on the market and domestic goods, and aggregate expenditure on child care. Given adding up, the

\footnotetext{
${ }^{27}$ Note that the standard approach to modelling labour supply implicitly assumes linear production functions for two types of domestic outputs (female and male leisures) and sets $\kappa_{\mathrm{i}}^{\mathrm{y}}=1$ and $\kappa_{\mathrm{i}}^{\mathrm{d}}=1$. This is clearly a special case, as are the assumptions that we adopt here.

${ }^{28}$ While, for the purposes of the present analysis, domestic human captial variables are assumed to be exogenous, in the longer term they may, for example, be dependent on institutional constraints supporting gender differences in work choices and unequal access to child care.
} 
expenditure share for the market good can be omitted. This leaves four equations for estimation:

$$
\begin{gathered}
S_{z}^{i}=\alpha_{z}^{i}(.)+\gamma_{z z}^{i} \ln w_{i}+\gamma_{z y}^{i} \ln \pi+\beta_{z}^{i} \ln \left(s_{i} / A_{i}(.)\right) \quad i=f, m \\
S_{y}={ }_{i}^{{ }^{3}} \alpha_{y}^{i}(.)+\gamma_{y z}^{i} \ln w_{i}+\gamma_{y y}^{i} \ln \pi+\beta_{y} \ln \left(s_{i} / A_{i}(.)\right)^{\prime} \Phi_{i} \\
+{ }^{\mathrm{X}}{ }^{3} \alpha_{y}^{k}(.)+\gamma_{y y}^{k} \ln \pi+\gamma_{y d}^{k} \ln \tau+\beta_{y} \ln \left(s_{k} / A_{k}(.)\right) \Phi_{k} \\
S_{d}={ }_{k}^{\mathrm{X}}{ }^{3} \alpha_{d}^{k}(.)+\gamma_{d h}^{k} \ln \pi+\gamma_{d d}^{k} \ln \tau+\beta_{d} \ln \left(s_{k} / A_{k}(.)\right) \Phi_{k}
\end{gathered}
$$

where $S_{y}={ }^{\mathrm{P}} S_{y}^{j} \Phi_{j}, S_{d}={ }^{\mathrm{P}} S_{d}^{k} \Phi_{k}$, and $\Phi_{j}=s_{j} / Y$ is individual $j$ 's proportional share of full income, $j=f, m, k$ and $k=1,2$. Conditions of parallel Engel curves on the aggregation of the domestic and market goods are imposed by setting $\beta_{y}^{j}=\beta_{y}$, for $j=f, m, k$ and $k=1,2$. We also set $a_{0}^{i}=9.0, i=f, m$, and $a_{0}^{k}=8.5, k=1,2$. As noted previously, adults are assumed to have the same preference parameters for the domestic and market goods, and the two children are assumed to have the same preference parameters for all goods. The implied restrictions on the preference parameters for the adults are: $\alpha_{y}^{f}=\alpha_{y}^{m}, \gamma_{y y}^{f}=\gamma_{y y}^{m}$ and $\gamma_{z y}^{f}=\gamma_{z y}^{m}$; and for the children: $\alpha_{y}^{1}=\alpha_{y}^{2}, \gamma_{y y}^{1}=\gamma_{y y}^{2}, \alpha_{d}^{1}=\alpha_{d}^{2}, \gamma_{d d}^{1}=\gamma_{d d}^{2}$ and $\gamma_{d y}^{1}=\gamma_{d y}^{2}$.

The model is first estimated on the dataset for households without children. The system reduces to the female and male leisure shares in (5.5) and the aggregate expenditure share for the domestic good in (5.6), for $j=f, m$. Following Gronau (1991), the preference parameters of adults in the model estimated on households with children are set at the values estimated for adults without children, to allow the preference parameters of children to be identified.

\subsection{Distribution rule}

The income shares, $s_{j}$, cannot be computed from the data due to the missing information on individual consumptions of the market and domestic goods, and so it is necessary to assume a distribution rule or select a functional form for the rule. We estimate the model for two special cases of a distribution rule which has the more general form

$$
s_{j}={ }_{i}^{\mathrm{X}} \phi^{i j}(.)\left(Y_{i}-{ }_{j}^{\mathrm{X}} A_{i j}-{ }_{k}^{\mathrm{X}} A_{i k}\right)+{ }_{i}^{\mathrm{X}} A_{i j} \quad j=f, m
$$




$$
s_{k}={ }_{i}^{\mathrm{X}} \phi^{i k}(.)\left(Y_{i}-{ }_{j}^{\mathrm{X}} A_{i j}-{ }_{k}^{\mathrm{X}} A_{i k}\right)+{ }_{i}^{\mathrm{X}} A_{i k} \quad k=1,2
$$

where $\phi^{i j}($.$) and \phi^{i k}($.$) are the shares of income above "subsistence" expenditures$ that adult $i$ transfers to member $j=f, m$ and $k=1,2$, and where ${ }_{k} \phi^{i k}()=$. $\left(1-{ }_{j}^{\mathrm{P}} \phi^{i j}().\right)$. A rule of this form implies that, in general, adult $i$ contributes to the "subsistence" expenditures of family members and then distributes the remaining or "supernumerary" income according to the share parameters $\phi^{i j}($.$) ,$ $j=f, m$, and $\phi^{i k}(),. k=1, \ldots, K$.

The rule nests a number of special cases. The first specialisation we introduce is that of zero lump sum transfers between adults. There are transfers only from adults to children. This implies setting $\phi^{i j}()=$.0 and $A_{i j}=0, j=f, m$. Under these parameter restrictions the income shares for members of the two-child family are

$$
\begin{gathered}
s_{i}=\phi^{i i}(.)\left(Y_{i}-A_{i}-{ }^{\mathrm{X}} A_{i k}\right)+A_{i} \quad i=f, m \\
s_{k}={ }_{i}^{\mathrm{X}} \phi^{i k}(.)\left(Y_{i}-A_{i}-{ }_{k}^{\mathrm{X}} A_{i k}\right)+{ }_{i}^{\mathrm{X}} A_{i k} \quad k=1,2
\end{gathered}
$$

In effect, adult $i$ supports own subsistence, $A_{i}$, and contributes $A_{i k}$ to each child's subsistence $A_{k}$, where $A_{k}={ }_{i} A_{i k}, i=f, m$, and transfers a share of supernumerary income, $\phi^{i k}($.$) , to each child. Thus the share of adult i$ 's supernumerary income transferred to both children is $\phi^{i k}()=.1-\phi^{i i}(),. k=1,2$. The constraint $A_{k}={ }_{i}^{\mathrm{P}} A_{i k}$ is imposed by defining ${ }_{k}^{\mathrm{P}} A_{f k}=\phi^{d}{ }_{k}^{\mathrm{P}} A_{k}$ and ${ }_{k}^{\mathrm{P}} A_{m k}=\left(1-\phi^{d}\right){ }_{k}^{\mathrm{P}} A_{k}$ , where $\phi^{d}$ is the proportion of the subsistence costs of the children supported by the mother and $\left(1-\phi^{d}\right)$ is the remaining proportion supported by the father. The $\phi^{d}$ is constrained to lie between zero and one by specifying $\phi^{d}=e^{\rho} /\left(1+e^{\rho}\right)$. The share $\phi^{i i}($.$) is also constrained to lie between zero and one by specifying$ $\phi^{i i}()=.e^{\nu^{i}(.)} /\left(1+e^{\nu^{i}(.)}\right)$. In addition we specify

$$
\nu^{i}(.)=\nu_{0}^{i}+\nu_{1}^{i}\left(Y_{f} / Y_{m}\right)
$$

to control for gender inequality in full incomes as an indicator of outside opportunities.

Results are presented for two versions of the rule defined by the parameter restrictions

(i) $\nu_{1}^{i}=0$ 
(ii) $\phi^{d}=0.5$

where the first implies that parents' transfers of supernumerary income to the children do not depend on the ratio of individual full incomes and the second that parents contribute equally to each child's cost of subsistence.

\subsection{Empirical results}

The adult preference parameters estimated on the sample of 425 households without children are listed in Table A1, Appendix A, assuming no intra-household transfers. The preference parameters of children and the parameters of the distribution rule are estimated on the sample of 481 two-child non-traditional households. The results are reported in Table A1, Appendix A, for versions (i) and (ii) of the distribution rule. For reasons of concavity we set $a_{y}^{0}=-1.0, a_{d}^{0}=-1.5$ and $\gamma_{y y}^{i}=\gamma_{y y}^{k}, i=f, m$ and $k=1,2$. On the production side of the model the cost function is concave at sample means. The demand systems are concave for almost all female and male records in the datasets on which the systems are estimated, and at sample means for children.

Table 3 reports intra-family income shares and consumption expenditures for non-traditional and traditional households, evaluated at data means. The column entitled "Child $k$ " gives the income share and consumption expenditures of each child, and so the figures need to be summed for $k=1,2$ to obtain the family's allocation to both children. Rows 1 to 3 report the results for version (i) of the distribution rule, and Rows 4 to 6 , for version (ii) of the rule. The income shares derived from the parameters of the rules suggest that both versions yield a similar overall outcome. There is a more unequal distribution of income between adults after child costs because of a greater contribution to the children by the female partner, with version (ii) leading to a slightly larger share of income to the children and therefore a more unequal distribution between adults.

Table 3 [here]

The results for the intra-family distribution of income are driven largely by the gender differences in data means for the time allocations to work and pure leisure noted in the preceding section. With the presence of children the leisure hours of both partners fall as we would expect, but the impact for females is greater than for males. Mean female and male leisure hours in households without children are 2731 and 2734, respectively, for the merged sample (Table 2). In non-traditional households, mean female and male leisure hours are 1842 and $2174 \mathrm{pa}$, and in traditional households, $1906 \mathrm{pa}$ and $2185 \mathrm{pa}$, respectively, in the merged sample. 
These data means suggest that, with the presence of children, women work much longer hours in domestic production and child care, and that overall they work longer hours than men. The changes in pure leisures, assuming similar preferences as indicated by the parameters estimated for adults, are consistent with a lower income for the female partner and hence the differential incidence of child costs on $f$ and $m$ as indicated by mean income shares.

Table 4 presents the income shares and subsistence parameters for versions (i) and (ii) of the distribution rule computed from the estimated parameters. The results for the system incorporating version (i) imply that the share of supernumerary income retained by the female partner is 0.3438 , and that retained by the male partner is 0.4444 , while the subsistence expenditures for both children are totally supported by the female partner $\left(\phi^{d}=1.0\right)$. However, from Table A2 it can be seen that the estimate of $\rho$, the parameter on which $\phi^{d}$ is defined, is not significant. It is for this reason that we estimate the system incorporating version (ii) of the rule which requires each partner to contribute equally to subsistence child costs, by setting $\phi^{d}=0.5$. In this version we also allow the retained share of supernumerary income to vary with the ratio of female to male initial full incomes. The table reports shares computed for $Y_{f} / Y_{m}=0.7395$ (the mean for the sample of non-traditional households), $Y_{f} / Y_{m}=0.7731$ (the mean for the sample of traditional households) and $Y_{f} / Y_{m}=1.0$ (equality). The figures indicate an allocation of a much larger share of the female partner's supernumerary income to the children. The results also suggest that the intra-family distribution of income is sensitive to the initial distribution of full incomes and, specifically, that the children's share of family income increases as the ratio of female to male initial full incomes rises.

Table 4 [here]

The expenditures of adults and children on domestic and market goods can be presented as full consumption costs as defined in (3.34) and (3.35) as opposed to shares, and that of child $k$ with respect to adult $i$ can be recorded as a full consumption equivalence scale as defined in (3.36). Table 5 reports the results in this form for the two versions of the distribution rule for each household type. Column 1 gives the mean full consumption costs for $f$ and $m$ and column 2 , the mean transfer to child $k$ from partner $i, i=f, m$, and the sum from both partners, $C_{k}$. Column 3 reports the full consumption equivalence scale for child $k$ obtained by dividing the sum of transfers, $C_{k}$ shown in column 2 , by the full consumption cost of each adult shown in column 1. The fact that the figures are much 
higher than most existing estimates of child costs and equivalence scales reflects of course the inclusion of domestic child care, as well as the domestic good. The wide differences between the full consumption equivalence scales computed with reference to each partner's full consumption expenditures reflect the differential incidence of child costs on adult members of the household, and underline the importance of taking an individualistic approach which models the distribution of income between parents as well as between parents and children.

Table 5 [here]

Market expenditures by family members in Table 3 indicate that in nontraditional households around 40 and 47 per cent of market income (depending on the choice of distribution rule) is allocated in total to the children. In traditional households the estimates are around 23 and 34 per cent. The higher estimates for non-traditional households can be explained in terms of the additional costs of market sector child care and consumption purchased as substitutes for domestic goods, associated with the labour force participation of the female partner as a second earner.

\section{Summary of results and discussion of approach}

In this paper we have sought to develop and apply a new approach to the measurement of child costs, based not on a model of an individual consumer but instead on a model of resource allocation in a multi-person household. We incorporate household production and define the "cost of a child" as the value of the consumption of market and domestically produced goods, together with the value of the parental time spent in child care, that are allocated to the child at the household equilibrium. Because this definition is far more comprehensive than the usual measure based only on consumption of market goods, our estimates of child costs are much higher than those found in existing studies.

In households with two children and the traditional market/household division of labour, the overall cost of both children's consumption of market goods is estimated to be around 23 and 34 per cent of that of the household, depending on the choice of distribution rule. These estimates increase to around 40 and 47 per cent in non-traditional households (in which the female partner works an average of 1508 hours per year). When the costs of parental time devoted to child care and domestically produced goods are added in, the value of both children's consumption allocation is estimated to be around 51 and 56 per cent of total 
consumption in the first kind of household, and around 49 and 54 per cent in the second.

Our approach allows us to distinguish between the transfers to children made by each adult in the household, differentiated as to the extent of the female partner's participation in the labour market. Taking the male's consumption as the benchmark, we find that when attention is restricted to market goods, our estimates of a child's consumption in a traditional household are 24 and 40 per cent of that of the adult male, for versions (i) and (ii) of the distribution rule, respectively. In non-traditional households the estimates rise to 53 and 69 per cent. One explanation for this is higher market purchase of "bought in" child care as well as higher transfers to the child from the employed mother. When the values of domestic production and parental child care are added into the child's consumption, the figures rise to 82 and 98 per cent of the total consumption of the adult male in traditional households, and 78 and 91 per cent in non-traditional households. These results underline the need to incorporate the time costs of child care and domestic work which, as the data given in Tables 1 and 2 show, are largely those of the female partner, into the estimation of child costs and strongly support the intuition that they are quantitatively very important.

Our procedure for obtaining these results can be summarised as follows. We have data on time allocations to child care. This allows the straightforward computation of domestic child care costs and their variations between household members and across household types. We have data on adult consumptions of pure leisure, but have to estimate the adult allocations of market and domestic consumption goods. We do this by assuming that adult preferences over own-consumption bundles are the same in households with and without children, specifying also an income sharing rule, and then estimating the adult preference parameters on data for households without children. Using data on the observed changes in individual leisure consumptions when the household acquires children, we are then able to impute corresponding changes in the allocations of income and consumption to the adults, and derive in turn estimates of the flow of consumption of household and market goods to the children. The data show that female leisure consumption falls by significantly more than that of the male when children are added to the household. This is interpreted to mean that the imputed income of the female in the household equilibrium also falls significantly relative to that of the male, so that a larger transfer to the children is made by females than by males.

Other interpretations are obviously possible. In the absence of data on individ- 
ual consumptions of market and household goods, alternative sets of assumptions could be made, leading to different results. The point of this paper is to suggest how child costs should be defined, and to set out a modelling methodology which can allow the costs so defined to be estimated. The variables in our model are in principle observable. In this paper we have tried to make clear the importance of recognising the assumptions that have to be made given the limitations of the available data, and the need for more information on the relevant variables. Further progress will be made only by confronting the problem that any set of assumptions is to a certain extent arbitrary, and that estimates of child costs (or equivalence scales) using existing data sets must be based, implicitly or, as here, explicitly, on such a set of assumptions.

\section{A ppendix A: Parameter estimates}

Table A1 presents results for the maximum likelihood estimation of the adult preference parameters on the sample of households without children. The upper half of the table lists the parameter estimates for the production side of the model while the lower half reports those for the demand system. Standard errors are shown in parenthesis.

Table A1 [here]

Table A2 reports the parameters of the systems estimated on the sample of non-traditional households with two children, incorporating adults preference parameters and versions (i) and (ii) of the distribution rule.

Table A2 [here]

The control variables in the production intercept are dummy variables for highest educational qualifications in the categories: bachelor degree or higher, $e^{1}$ for the female partner and $e^{2}$ for the male partner; and completed highest level of secondary school available and/or obtained post school certificate, diploma, trade or apprenticeship, $e^{3}$ for the female partner and $e^{4}$ for the male partner. 


\section{R eferences}

ABS (1993), Time Use Survey Australia, User's Guide, Cat. No. 4150.0.

Angrist, J.D. and A.B.Krueger (1992), "The Effect of Age at School Entry on Educational Attainment: An Application of Instrumental Variables with Moments from Two Samples", J ournal of the American Statistical A ssociation, 87, 328-336.

Apps, P.F. and R.Rees (1999), "On the Taxation of Trade within and between households", J ournal of Public Economics, 35, 355-369.

Apps, P.F. and R.Rees (1997), "Collective Labor Supply and Household Production", J ournal of Political E conomy, 105, 178-190.

Apps, P.F. and R.Rees (1988), "Taxation and the Household", J ournal of Public E conomics, 35, 155-169.

Arellano, M. and C.Meghir (1992), "Female Labour Supply and On-the-Job Search: An Empirical Model Estimated Using Complimentary Data Sets", Review of Economic Studies, 59, 537-557.

Becker, G.S. (1965), "A Theory of the Allocation of Time", E conomic J ournal, 75, 493-517.

Browning, M. (1992), "Children and Household Economic Behaviour", J ournal of Economic Literature, 30, 1434-1475.

Gronau, R. (1991) 'The Intrafamily Allocation of Goods - How to Separate the Adult from the Child", J ournal of Labor Economics, 9, 207-235.

Kapteyn, A. and B.Van Praag (1976), "A New Approach to the Construction of Family Equivalence Scales", European E conomic Review, 7, 365-371.

Nelson, J.A. (1993), Household Equivalence Scales: Theory versus Policy?" J ournal of Labor Economics, 11, 471-493.

Pollak R.A. and T.J.Wales (1992), Demand System Specification and E stimation, Oxford University Press, Oxford.

Pollak R.A. and T.J.Wales (1979), "Welfare Comparisons and Equivalence Scales", American Economic Review, 69, 216-221. 
Table 1: Data means for matching samples (standard deviations in parentheses)

\begin{tabular}{|c|c|c|c|c|c|c|c|}
\hline & \multicolumn{4}{|c|}{ Households with two children } & \multirow{2}{*}{\multicolumn{2}{|c|}{$\begin{array}{l}\text { H'holds with } \\
\text { no children }\end{array}$}} \\
\hline & & \multicolumn{2}{|c|}{ Non-traditional } & \multicolumn{2}{|c|}{ Traditional } & & \\
\hline \multicolumn{8}{|c|}{ IDS data means } \\
\hline 1 & Market work, hours pa & 1508 & $(572)$ & 48 & $(118)$ & 2001 & $(418)$ \\
\hline 2 & Gross wage $\$$ & 11.18 & $(4.91)$ & $11.60^{*}$ & $(4.22)$ & 11.62 & $(3.67)$ \\
\hline 3 & Non-labour income $\$ p a$ & 577 & $(1720)$ & 687 & $(2415)$ & 323 & $(815)$ \\
\hline & Male & & & & & & \\
\hline 4 & Market work, hours pa & 2305 & $(317)$ & 2285 & $(314)$ & 2277 & $(303)$ \\
\hline 5 & Gross wage $\$$ & 15.20 & $(4.9)$ & 15.28 & $(5.29)$ & 13.69 & $(4.58)$ \\
\hline & Non-labour income $\$ p a$ & 463 & $(2056)$ & 340 & $(1120)$ & 298 & $(710)$ \\
\hline \multicolumn{2}{|c|}{ Number of records } & 481 & & 572 & & 425 & \\
\hline $\begin{array}{l}\text { Female } \\
\end{array}$ & \multicolumn{7}{|c|}{ TUS data means } \\
\hline 7 & Domestic work, hours pa & 1567 & $(795)$ & 1920 & $(675)$ & 1088 & $(708)$ \\
\hline 8 & Child care, hours pa & 1025 & $(892)$ & 1872 & (1209) & - & - \\
\hline 9 & Pure leisure hours pa & 1795 & (1109) & 1945 & $(1317)$ & 2757 & $(1022)$ \\
\hline & Male & & & & & & \\
\hline 10 & Domestic work, hours pa & 763 & $(767)$ & 673 & $(619)$ & 771 & $(690)$ \\
\hline & Child care, hours pa & 488 & $(583)$ & 554 & $(651)$ & - & - \\
\hline & Pure leisure hours pa & 2161 & $(1234)$ & 2279 & $(1242)$ & 2726 & $(1161)$ \\
\hline & aber of records & 175 & & 178 & & 153 & \\
\hline
\end{tabular}

* Estimated

Table 2: Data means of merged data sets

\begin{tabular}{|l|cc|cc|cc|}
\cline { 2 - 5 } \multicolumn{1}{c|}{} & \multicolumn{3}{c|}{ Households with two children } & \multicolumn{2}{c|}{\begin{tabular}{c} 
'holds with \\
\cline { 2 - 5 }
\end{tabular}} & \multicolumn{2}{c|}{ Non-traditional } & \multicolumn{2}{c|}{ Traditional } & \multicolumn{2}{c}{ no children } \\
\hline & Female & M ale & Female & M ale & Female & M ale \\
2 Child care, hrs pa & 1396 & 825 & 1851 & 695 & 1108 & 829 \\
3 Leisure hours pa & 1093 & 536 & 2036 & 678 & - & - \\
4 Leisure expenditure \$pa & 1842 & 2174 & 1906 & 2185 & 2731 & 2734 \\
& 20597 & 32965 & 22117 & 32968 & 31847 & 37394 \\
5 Child care exp \$pa & Child $k$ & & Child $k$ & & & \\
\hline
\end{tabular}


Table 3: Intra-household income shares and expenditures

\begin{tabular}{|c|c|c|c|c|c|c|}
\hline & \multicolumn{3}{|c|}{ Non-traditional households } & \multicolumn{3}{|c|}{ Traditional households } \\
\hline & Female & Male & Child $k$ & Female & Male & Child $k$ \\
\hline (i) $v_{1}^{i}=0$ & & & & & & \\
\hline 1 Income share $\$ \mathrm{pa}$ & 40086 & 64772 & 25061 & 41229 & 64365 & 25691 \\
\hline 2 Domestic good exp $\$ p a$ & 7820 & 11890 & 4203 & 8625 & 14213 & 4627 \\
\hline $\begin{array}{l}3 \text { Market good exp } \$ \mathrm{pa} \\
\text { (ii) } \phi^{d}=0.5\end{array}$ & 11669 & 19917 & 10632 & 10487 & 17184 & 4079 \\
\hline 4 Income share \$pa & 37644 & 62783 & 27231 & 38452 & 61827 & 28351 \\
\hline 5 Domestic good exp $\$$ pa & 7509 & 11594 & 4506 & 8017 & 13589 & 5243 \\
\hline 6 Market good exp $\$ p a$ & 9538 & 18224 & 12544 & 8318 & 15270 & 6120 \\
\hline
\end{tabular}

Table 4: Distribution rule parameters

\begin{tabular}{|c|c|c|c|}
\hline Distributional rule & $\phi^{f f}$ & $\phi^{m m}$ & $\phi^{d}$ \\
\hline$\nu_{1}^{i}=0$ & 0.3438 & 0.4444 & 1.0 \\
\hline$\phi^{d}=0.5$ & & & \\
\hline$Y^{f} / Y^{m}=0.7395^{*}$ & 0.0817 & 0.5053 & 0.5 \\
\hline$Y^{f} / Y^{m}=0.7731^{* *}$ & 0.0674 & 0.4965 & 0.5 \\
\hline$Y^{f} / Y^{m}=1.0$ & 0.0179 & 0.4376 & 0.5 \\
\hline
\end{tabular}

*mean for non-traditional households

**mean for traditional households 
Table 5: Full consumption equivalence scales

\begin{tabular}{|lccc|}
\hline & $\begin{array}{c}\text { A dult full cons. } \\
\text { cost } C_{i} \$ \text { pa }\end{array}$ & $\begin{array}{c}\text { Transfer to } \\
\text { child } k \text { pa }\end{array}$ & $\begin{array}{c}C_{k} / C_{i} \\
i=f, m\end{array}$ \\
\hline $\begin{array}{l}\text { Non-traditional h'holds } \\
\text { (i) } \nu_{1}^{i}=0\end{array}$ & & & \\
Female partner & 19489 & 12880 & 1.2836 \\
Male partner & 31807 & 12136 & 0.7865 \\
$C_{k}$ & - & 25016 & - \\
(ii) $\phi^{d}=0.5$ & & & \\
Female partner & 17047 & 14101 & 1.5975 \\
Male partner & 29818 & 13131 & 0.9133 \\
$C_{k}$ & - & 27232 & - \\
\hline Traditional households & & & \\
(i) $\nu_{1}^{i}=0$ & & & \\
Female partner & 19112 & 13593 & 1.3390 \\
Male partner & 31397 & 12049 & 0.8151 \\
$C_{k}$ & - & 25591 & - \\
(ii) $\phi^{d}=0.5$ & & & \\
Female partner & 16335 & 14981 & 1.7356 \\
Male partner & 28859 & 13318 & 0.9824 \\
$C_{k}$ & - & 28351 & - \\
\hline
\end{tabular}


Table A 1: Parameter estimates: households with no children

\begin{tabular}{|lcc|}
\hline Parameter & Estimate & (Std err) \\
\hline Production system & & \\
$a_{f}^{y 0}$ & 0.6240 & $(0.0048)$ \\
$a_{f}^{y 1}\left(e^{1}\right)$ & -0.0201 & $(0.0054)$ \\
$a_{f}^{y 2}\left(e^{2}\right)$ & -0.0357 & $(0.0060)$ \\
$a_{f}^{y 3}\left(e^{3}\right)$ & -0.0392 & $(0.0037)$ \\
$a_{f}^{y 4}\left(e^{4}\right)$ & -0.0337 & $(0.0047)$ \\
$a_{i i}^{y}=-a_{i j}^{y} \quad i=f, m$ & 0.02418 & $(0.0063)$ \\
Demand system & & \\
$\alpha_{z}^{f 0}$ & 0.6466 & $(0.0307)$ \\
$\alpha_{z}^{f 1}(\ln \eta)$ & -0.0746 & $(0.0095)$ \\
$\alpha_{z}^{m 0}$ & 0.5058 & $(0.0307)$ \\
$\alpha_{z}^{m 1}(\ln \eta)$ & -0.0222 & $(0.0113)$ \\
$\alpha_{y}^{i 0} \quad i=f, m$ & 0.0446 & $(0.0247)$ \\
$\alpha_{y}^{i 1}(\ln \eta) \quad i=f, m$ & 0.0478 & $(0.0074)$ \\
$\beta_{z}^{f}$ & -0.2554 & $(0.0235)$ \\
$\beta_{z}^{m}$ & -0.2188 & $(0.0645)$ \\
$\beta_{y}^{i} \quad i=f, m$ & -0.0363 & $(0.0097)$ \\
$\gamma_{z z}^{f}$ & 0.1155 & $(0.0094)$ \\
$\gamma_{z z}^{m}$ & 0.0930 & $(0.0154)$ \\
$\gamma_{z y}^{i} \quad i=f, m$ & -0.0464 & $(0.0091)$ \\
$\gamma_{y y}^{i} \quad i=f, m$ & 0.0682 & $(0.0071)$ \\
$L o g L$ & 3683.30 & \\
\hline Number of records & 425 & \\
\hline
\end{tabular}


Table A 2: Parameter estimates: two-child households

\begin{tabular}{|c|c|c|c|c|}
\hline Distribution rule & (i) $\nu_{1}^{i}=0$ & & (ii) $\phi^{d}=0.5$ & \\
\hline Parameter & Estimate & (Std err) & Estimate & (Std error) \\
\hline \multicolumn{5}{|l|}{ Production system } \\
\hline$a_{f}^{y 0}$ & 0.6260 & $(0.0073)$ & 0.6360 & $(0.0059)$ \\
\hline$a_{f}^{y 1}\left(e^{1}\right)$ & -0.0118 & $(0.0121)$ & -0.0205 & $(0.0079)$ \\
\hline$a_{f}^{y 2}\left(e^{2}\right)$ & -0.0338 & $(0.0175)$ & -0.0357 & $(0.0066)$ \\
\hline$a_{f}^{y 3}\left(e^{3}\right)$ & -0.0346 & $(0.0065)$ & -0.0388 & $(0.0058)$ \\
\hline$a_{f}^{y 4}\left(e^{4}\right)$ & 0.0263 & $(0.0050)$ & 0.0243 & $(0.0047)$ \\
\hline$a_{i i}^{y}=-a_{i j}^{y} \quad i, j=f, m$ & 0.2088 & $(0.0098)$ & 0.2179 & $(0.0058)$ \\
\hline$a_{f}^{d 0}$ & 0.6129 & $(0.0207)$ & 0.6259 & $(0.0107)$ \\
\hline$a_{f}^{d 1}\left(e^{1}\right)$ & 0.0609 & $(0.0399)$ & 0.0525 & $(0.0161)$ \\
\hline$a_{f}^{d 2}\left(e^{2}\right)$ & -0.0541 & $(0.0300)$ & -0.0532 & $(0.0132)$ \\
\hline$a_{f}^{d 3}\left(e^{3}\right)$ & 0.0224 & $(0.0124)$ & 0.0115 & $(0.0115)$ \\
\hline$a_{f}^{d 4}\left(e^{4}\right)$ & 0.0543 & $(0.0227)$ & 0.0532 & $(0.0094)$ \\
\hline$a_{i i}^{d}=-a_{i j}^{d} \quad i, j=f, m$ & 0.2102 & $(.0089)$ & 0.2233 & $(0.0090)$ \\
\hline \multicolumn{5}{|l|}{ Demand system } \\
\hline$\alpha_{y}^{k 0}$ & 0.1971 & $(0.0190)$ & 0.1883 & $(0.0118)$ \\
\hline$\alpha_{u}^{k}(\ln \psi)$ & -0.0293 & $(0.0129)$ & -0.0238 & $(0.0040)$ \\
\hline$\alpha_{d}^{k 0}$ & 0.6096 & $(0.0334)$ & 0.5530 & $(0.0211)$ \\
\hline$\alpha_{d}^{k 1}(\ln \psi)$ & -0.1302 & $(0.0082)$ & -0.0976 & $(0.0066)$ \\
\hline$\beta_{d}^{k}$ & -0.1215 & $(0.539)$ & -0.1662 & $(0.0312)$ \\
\hline$\gamma_{d d}^{k}$ & 0.0324 & $(0.0356)$ & 0.0597 & $(0.0166)$ \\
\hline$\gamma_{d y}^{k}$ & -0.0345 & $(0.0086)$ & -0.0376 & $(0.0057)$ \\
\hline$\rho$ & 21.413 & $(2509.0)$ & - & - \\
\hline$\nu_{0}^{f}$ & -0.6464 & $(0.2247)$ & 2.0858 & $(0.8336)$ \\
\hline$\nu_{1}^{f}$ & - & - & -6.0993 & $(1.5859)$ \\
\hline$\nu_{0}^{m}$ & -0.2233 & $(0.0551)$ & 0.7935 & $(0.1630)$ \\
\hline$\nu_{1}^{m}$ & - & - & -1.044 & $(0.2088)$ \\
\hline $\log L$ & 5528.51 & & & \\
\hline Number of records & 481 & & 481 & \\
\hline
\end{tabular}




\section{IZA Discussion Papers}

No. Author(s)

51

A. Barrett

P. J. O'Connell

52 J. Mayer

R. T. Riphahn

53

J. Hartog

P. T. Pereira

J. A. C. Vieira

54 M. Lofstrom

55

L. Goerke

56

A. Lindbeck

D. J. Snower

57

I. N. Gang

K. F. Zimmermann

58

T. Bauer

K. F. Zimmermann

59

D. J. DeVoretz

S. A. Laryea

60

C. Belzil

J. Hansen

61

R. Winkelmann

62

A. Thalmaier

63

M. Ward

64

M. Ward

65

H. Lehmann

J. Wadsworth

A. Acquisti

66

E. J. Bird

H. Kayser

J. R. Frick

G. G. Wagner
Title

Area

Date

Does Training Generally Work?

5

$8 / 99$

The Returns to In-Company Training

Fertility Assimilation of Immigrants: Evidence

3

$8 / 99$

from Count Data Models

Inter-industry Wage Dispersion in Portugal: high

but falling

$8 / 99$

Labor Market Assimilation and the

$8 / 99$

Self-Employment Decision of Immigrant

Entrepreneurs

Value-added Tax versus Social Security

Contributions

Centralized Bargaining and Reorganized Work:

Are they compatible?

Is Child like Parent?

Educational Attainment and Ethnic Origin

9/99

Occupational Mobility of Ethnic Migrants

$9 / 99$

Canadian Immigration Experience:

Any Lessons for Europe?

Subjective Discount Rates, Intergenerational

Transfers and the Return to Schooling

Immigration: The New Zealand Experience

$10 / 99$

Bestimmungsgründe von Fehlzeiten: Welche

Rolle spielt die Arbeitslosigkeit?

1/2/3 9/99

6

$10 / 99$

Your Everyday, Average Academic

$10 / 99$

Salary and the Gender Salary Gap in the Academic Profession

Grime and Punishment: Job Insecurity and Wage 4

Arrears in the Russian Federation

$10 / 99$

The Immigrant Welfare Effect: Take-Up or

3

$10 / 99$ 

of Wage Differentials Transition Economies

\section{0 \\ J. C. van Ours}

J. Veenman
The Netherlands: Old Emigrants - Young Immigrant Country

Migration, Migrants and Policy in the United Kingdom

Privacy, time consistent optimal labor income taxation and education policy

Female Labour Supply, Flexibility of Working Hours, 1 and Job Mobility in the Netherlands

The Heterogeneity and Cyclical Sensitivity of 1 Unemployment: An Exploration of German Labor Market Flows 

Adversity

91 M. Lechner

Tenures that Shook the World: Worker Turnover in $\quad 4$ Russia, Poland and Britain

Identification and Estimation of Causal Effects of

An Evaluation of Public-Sector-Sponsored

Continuous Vocational Training Programs in East

N. Smith 
107 J. C. van Ours G. Ridder

J. Boone

J. C. van Ours

109 G. J. van den Berg

B. van der Klaauw

110 D. DeVoretz

C. Werner

111 V. Sorm

K. Terrell

L. Bellmann

T. Schank

113 R. Euwals

114 G. Brunello

A. Medio

115 A. Cigno

F. C. Rosati

116

C. Belzil

A. Haas

C. Klose

118 M. A. Shields

M. E. Ward

119 A. Lindbeck

D. J. Snower

120 P. T. Pereira

P. S. Martins

121 J. C. van Ours
Fast Track or Failure: A Study of the Completion

Rates of Graduate Students in Economics

Modeling Financial Incentives to Get Unemployed Back to Work

Combining Micro and Macro Unemployment

3

$1 / 00$

Duration Data

A Theory of Social Forces and Immigrant Second

1

$2 / 00$

Language Acquisition

Sectoral Restructuring and Labor Mobility:

A Comparative Look at the Czech Republic

Innovations, Wages and Demand for

5

$2 / 00$

Heterogeneous Labour: New Evidence from a

Matched Employer-Employee Data-Set

Do Mandatory Pensions Decrease Household

Savings? Evidence for the Netherlands

An Explanation of International Differences in

Education and Workplace Training

Why do Indian Children Work, and is it Bad for

3

$2 / 00$

Them?

Unemployment Insurance and Subsequent Job

3

$2 / 00$

Duration: Job Matching vs. Unobserved

Heterogeneity

IAB Employment Subsample 1975-1995.

Opportunities for Analysis Provided by the

Anonymised Subsample

Improving Nurse Retention in the British National

5

$2 / 00$

Health Service: The Impact of Job Satisfaction on Intentions to Quit

The Division of Labor and the Market for

Organizations

Does Education Reduce Wage Inequality?

5

Quantile Regressions Evidence from Fifteen

European Countries

Do Active Labor Market Policies Help Unemployed Workers to Find and Keep Regular Jobs? 
Rational Poverty or Poor Rationality? The Take-up of Social Assistance Benefits

125 F. Büchel

The Income Portfolio of Immigrants in Germany -

Effects of Ethnic Origin and Assimilation. Or:

J. R. Frick

126 J. Fersterer

R. Winter-Ebmer

Who Gains from Income Re-Distribution?

127 M. Karanassou

D. J. Snower

Smoking, Discount Rates, and Returns to

Education

Characteristics of Unemployment Dynamics: The

Chain Reaction Approach

128 O. Ashenfelter

D. Ashmore

O. Deschênes

Do Unemployment Insurance Recipients Actively

Seek Work? Evidence From Randomized Trials in

Four U.S. States

129 B. R. Chiswick

M. E. Hurst

C. Lucifora

The Employment, Unemployment and Unemployment Compensation Benefits of Immigrants

The Returns to Education in Italy: A New Look at the Evidence

Are Immigrants Favorably Self-Selected? An

134 A. D. Kugler

G. Saint-Paul

135 A. Barrett P. J. O'Connell

136 M. Bräuninger M. Pannenberg

Is There a Wage Premium for Returning Irish

Unemployment and Productivity Growth: An

Empirical Analysis within the Augmented Solow 
141 R. Hujer

M. Wellner

142

J. J. Dolado

F. Felgueroso

J. F. Jimeno

143 P. J. Luke

M. E. Schaffer

144 G. Saint-Paul

145 M.-S. Yun

146 T. K. Bauer

J. P. Haisken-DeNew

147 M. Belot

J. C. van Ours

148 L. Goerke

149 R. Lalive

J. C. van Ours

J. Zweimüller

150 J. DiNardo

K. F. Hallock

J.-St. Pischke

151 M. Ward

152 J. J. Dolado

F. Felgueroso

J. F. Jimeno

153 A. S. Kalwij

M. Gregory

154 Michael Gerfin Michael Lechner

155 J. Hansen

156 C. Dustmann

F. Fabbri

157 P. Apps

R. Rees
The Effects of Public Sector Sponsored Training on

Individual Employment Performance in East

Germany

Explaining Youth Labor Market Problems in Spain: 3

$4 / 00$

Crowding-Out, Institutions, or Technology Shifts?

Wage Determination in Russia: An Econometric

Investigation

Flexibility vs. Rigidity: Does Spain have the worst of 1 both Worlds?

Decomposition Analysis for a Binary Choice Model 7

$4 / 00$

Employer Learning and the Returns to Schooling

5

$4 / 00$

Does the Recent Success of Some OECD

Countries in Lowering their Unemployment Rates

Lie in the Clever Design of their Labour Market

Reforms?

Employment Effects of Labour Taxation in an Efficiency Wage Model with Alternative Budget

Constraints and Time Horizons

The Impact of Active Labor Market Programs and

Benefit Entitlement Rules on the Duration of Unemployment

Unions and the Labor Market for Managers

7

$5 / 00$

Gender, Salary and Promotion in the Academic Profession

The Role of the Minimum Wage in the Welfare 3

State: An Appraisal

Overtime Hours in Great Britain over the Period 3

$5 / 00$

1975-1999: A Panel Data Analysis

Microeconometric Evaluation of the Active Labour 6 Market Policy in Switzerland

$5 / 00$

The Duration of Immigrants' Unemployment Spells: $\quad 1 / 3 \quad 5 / 00$

Evidence from Sweden

Language Proficiency and Labour Market Per- 1

$5 / 00$

formance of Immigrants in the UK

Household Production, Full Consumption and

7

$5 / 00$ the Costs of Children 